\title{
Influence of the proximal screws of buttress plates on the stability of vertical femoral neck fractures: a finite element analysis
}

Shi Zhan ${ }^{1 \dagger}$, Dajun Jiang ${ }^{1+}$, Jian Xu' ${ }^{1}$, Ming Ling ${ }^{2}$, Kai Yang ${ }^{3}$, Yuehua $\mathrm{Li}^{3}$, Weitao Jia ${ }^{4^{*}}$, Hai Hu $\mathrm{H}^{1,4^{*}}$ (D) and Changqing Zhang ${ }^{1,4^{*}}$

\begin{abstract}
Background: The treatment of vertical femoral neck fractures (VFNFs) in young patients remains challenging, with a high complication rate by using traditional techniques. The use of cannulated screws (CSs) combined with a buttress plate represents an alternative approach for treating VFNFs. However, the biomechanical influence of the use or non-use of the proximal screws of buttress plates on vFNFs stability remains unclear. This study aims to analyse the biomechanics of buttress plate fixation with or without the use of proximal screws through finite element analysis (FEA) to further understand this approach.
\end{abstract}

Methods: We built five VFNFs (Pauwels angle $70^{\circ}$ ) finite element models treated using three cannulated screws (CS group) or three cannulated screws plus a locking buttress plate (buttress group). In the buttress group, use or nonuse of proximal screws was carried out on two types of plates (4-hole \& 6-hole). The following seven parameters were analysed to compare biomechanical properties of the five models: the stiffness; the maximal stress of the plate system (plate and screws), CSs and bone (MPS, MCS, MBS); the maximal displacement of internal fixations (plate system \& CSs) and bone (MIFD, MBD); and the maximal relative displacement of interfragments (MID).

Results: Compared with CS model, the buttress models exhibited improved biomechanical properties, with increased stiffness and decreased MCS, MBS, MIFD, MBD and MID. The models fixed using buttress plates combined with a proximal screw showed greater stiffness $(+3.75 \% \&+8.31 \%$ vs $+0.98 \% \&+4.57 \%)$ and MPS $(795.6 \& 947.2$ MPa vs 294.9 \& $556.2 \mathrm{MPa})$ values, and smaller MCS, MBS, MIFD, MBD and MID (- $3.41 \%$ to $-15.35 \%$ vs $-0.07 \%$ to $-4.32 \%)$ values than those using the same length plates without a proximal screw.

(Continued on next page)

\footnotetext{
* Correspondence: jiaweitao@shsmu.edu.cn; xmhuhai@hotmail.com; zhangcq@sjtu.edu.cn

${ }^{\dagger}$ Shi Zhan and Dajun Jiang are authors contributed equally to this work and should be considered co-first authors.

${ }^{4}$ Department of Orthopedic Surgery, Shanghai Jiaotong University Affiliated

Sixth People's Hospital, Shanghai 200233, People's Republic of China 'Orthopedic Biomechanical Laboratory of Department of Orthopedic Surgery, Shanghai Jiao Tong University Affiliated Sixth People's Hospital, NO. 600, Yishan Rd., Shanghai 200233, People's Republic of China

Full list of author information is available at the end of the article
}

(c) The Author(s). 2020 Open Access This article is licensed under a Creative Commons Attribution 4.0 International License, which permits use, sharing, adaptation, distribution and reproduction in any medium or format, as long as you give appropriate credit to the original author(s) and the source, provide a link to the Creative Commons licence, and indicate if changes were made. The images or other third party material in this article are included in the article's Creative Commons licence, unless indicated otherwise in a credit line to the material. If material is not included in the article's Creative Commons licence and your intended use is not permitted by statutory regulation or exceeds the permitted use, you will need to obtain permission directly from the copyright holder. To view a copy of this licence, visit http://creativecommons.org/licenses/by/4.0/ The Creative Commons Public Domain Dedication waiver (http://creativecommons.org/publicdomain/zero/1.0/) applies to the data made available in this article, unless otherwise stated in a credit line to the data. 
(Continued from previous page)

Conclusions: Based on the FEA results, buttress plates can improve construct mechanics, help to resist shear force and prevent varus collapse; under the modelling conditions, the use of a proximal screw on buttress plate may be a key technical feature in improving anti-shearing ability; additionally, this screw may be essential to reduce stress and prevent re-displacement of cannulated screws and fracture fragments.

Keywords: Vertical femoral neck fracture, Buttress plate, Proximal screw, Biomechanics, Finite element analysis

\section{Highlights}

We describe biomechanical analysis of the buttress plate.

The buttress plate provides improved initial stability of vertical femoral neck fractures.

The proximal screw of the buttress plate is key for mechanical transmission of force when treating vertical femoral neck fractures.

\section{Introduction}

The treatment of vertical femoral neck fractures (vFNFs, Pauwels type III) in young adults is challenging because this type of fracture, which usually results from highenergy trauma, is subject to high shear forces, leading high rates of non-union and osteonecrosis [1, 2]. Additionally, most vFNFs are comminuted and are mostly centred in the inferior and posterior quadrants, resulting in difficulties reconstituting the bony buttress [3]. To achieve satisfactory treatment of this type of fracture, anatomic reduction and stable internal fixation are necessary [4]. However, failure after fixation has been seen using essentially all devices, including cannulated screws in various configurations, sliding hip screws with or without additional derotation screws, cephalomedullary nails, and proximal femoral locking plates, and the failure rate of surgery for vFNFs remains high $[1,3,5]$.

The potential application of a buttress plate to improve the fixation stability of vFNFs was first suggested by Mir and Collinge [6]. With the help of the buttress plate, the shear force can be converted into compressive forces to achieve medial buttress stability. The utility and safety of the buttress plate have been validated in previous studies [7-10]. However, there is no consensus on the use of a proximal screw on the buttress plate, there are no detailed usage guidelines. On the one hand, Mir and Collinge hypothesized the non-use of proximal screws because the use of a buttress plate may be sufficient to reduce shear effects [6]. Additionally, to reproduce a specific clinical situation, Giordano et al. did not use a proximal screw in the head [11]. On the other hand, Kunapuli et al. performed an experimental study by using cannulated screws or a DHS, augmented by a $2.7 \mathrm{~mm}$ locking plate with a proximal screw, resulting in positively [7]. Furthermore, Ye et al. [9] also used a proximal screw and indicated that the screw proximal to the fracture line should be directed cephalad into the femoral head to avoid crossing the fracture line, only changing the locking plate to an unlocking plate. They argued that locked screws may prevent the dynamic compression between the fracture fragments postoperatively and may increase the risk of non-union; however, there were still 3 out of 27 patients who experienced implant failure, and associated with femoral neck shortening. Thus, how the use of a proximal screw on the buttress plate affects the overall stability of surgically treated vFNFs is an interesting question. The present study aimed to evaluate the benefits of the buttress plate and its implications in vFNFs treatment and to verify the influences of the use of a proximal screw on the stability of vFNFs through finite element analysis. This work will help orthopaedic surgeons to further understand the biomechanical properties of buttress plates and proximal screws, enabling appropriate clinical decision making for the treatment of vFNFs.

\section{Materials and methods \\ Modelling of femoral neck fractures}

Computed tomography images (SOMATOM Definition AS1; Siemens, thickness, $0.6 \mathrm{~mm}$; resolution, $512 \times 512$ pixels) of a Sawbone femur (Model 3402, 4th Generation Sawbone, Vashon, WA, USA) were obtained and imported into Mimics 19.0 (The Materialise Group, Leuven, Belgium) to create a three-dimensional model. The model was cut with a modified Pauwels angle of 70 degrees in 3-Matic (version 11.0 Materialise, Leuven, Belgium) to simulate a Pauwels type III femoral neck fracture. Sawbone femurs were chosen because they have been validated to minimize individual variations and have been confirmed to be a suitable replacement for cadavers [12-14].

\section{Modelling of internal fixation for femoral neck fractures} Since four to six-hole buttress plates are commonly used in the clinic [9] and thin plates may reduce the possible irritation to medial femoral neck structures [7], fourand six-hole $2.7 \mathrm{~mm}$ locking plates [7, 10] were adopted in this study. The buttress plate, $3.5 \mathrm{~mm}$ screws (plate screw) and $6.5 \mathrm{~mm}$ cannulated screws (Stryker, Mahwah, NJ, USA) were created in SolidWorks2014 (DS SolidWorks Corp, Waltham, MA, USA) based on real geometrical dimensions. The three cannulated screws, of 
which two $90 \mathrm{~mm}$ cannulated screws were inserted into the femoral proximal region and one $100 \mathrm{~mm}$ cannulated screw was inserted into the distal region, were inserted in parallel to form an inverted isosceles triangular configuration (PIIT). And all the buttress plates were placed in a standard medial position, as shown in previous studies $[9,10]$. Five internal fixation models were built (Fig. 1) and named PIIT, PIIT+4HI, PIIT+4HI-1, PIIT+6HI and PIIT+6HI-1. We considered PIIT as the control because it is commonly used in clinical practice and is considered to provide good biomechanical stability [15]. In PIIT+4HI, PIIT+4HI-1, PIIT+6HI and PIIT+ $6 \mathrm{HI}-1$, a four- or six-hole buttress plate was applied over the apex of fracture with or without a screw in the proximal region (Fig. 1).

\section{Material properties and boundary conditions}

The Sawbone femur was assumed to be linear, elastic, and isotropic. For cortical and cancellous bones, the Young's moduli (E) were 17.0 and $0.0155 \mathrm{GPa}$ and Poisson's ratios (v) were 0.3 and 0.3 , respectively. The number of nodes (ranging from 135,967 to 156,165) and elements (ranging from 601,304 to 672,502) for all models were recorded and are detailed in Table 1 . A four-node tetrahedron body element (C3D4) was used for the bone, plates, and screws, similar to other studies $[16,17]$.

The slipping friction factor of the interface between two fracture surfaces was set to 0.46 , and the corresponding factor for the interface of the bone and plate was set to 0.3 [18]. A $2100 \mathrm{~N}$ load corresponding to $300 \%$ body weight $[10,19]$ was uniformly applied to the weight-bearing region of the femoral head along the mechanical axis (Fig. 2). Freedom of the distal femur, which had a length of $108 \mathrm{~mm}$, was bounded. All models were simulated using Abaqus 6.13 (Simulia Corp, Providence, RI, USA).

\section{Parameters for analysis}

The following parameters were used for analysis: the stiffness (representing the whole stability [20, 21]), the maximal stress of the plate system (plate and screws), cannulated screws (CS), and bone (MPS, MCS, and MBS, respectively); and the maximal displacement of internal fixation (plate system and CS) and bone (MIFD and MBD, respectively), which were the same as in the previous study [10]. The maximal relative displacement of interfragments (MID) (representing the interfragmentary shear stability [22]) was also analysed. All values were compared between the buttress group and the CS group (Table 2) except for MPS, and the corresponding variation rates were calculated by the following formula:

$$
\mathrm{VR}=\frac{\mathrm{BV}-\mathrm{CV}}{\mathrm{CV}} \times 100 \%
$$

where $\mathrm{VR}=$ variation rate, $\mathrm{BV}=$ value for the buttress group, and $\mathrm{CV}=$ value for the $\mathrm{CS}$ group.

\section{Results}

\section{Stiffness}

The stiffness of the models with a proximal screw was superior to that of models without a proximal screw (Table 2). The variation rates of stiffness in the models with a proximal screw $(\mathrm{PIIT}+4 \mathrm{HI} \& \mathrm{PIIT}+6 \mathrm{HI})$ were + $3.75 \%$ and $+8.31 \%$, while those in the models without a proximal screw (PIIT+4HI-1 \& PIIT+6HI-1) were + $0.98 \%$ and $4.57 \%$. Maximal stiffness was observed in the

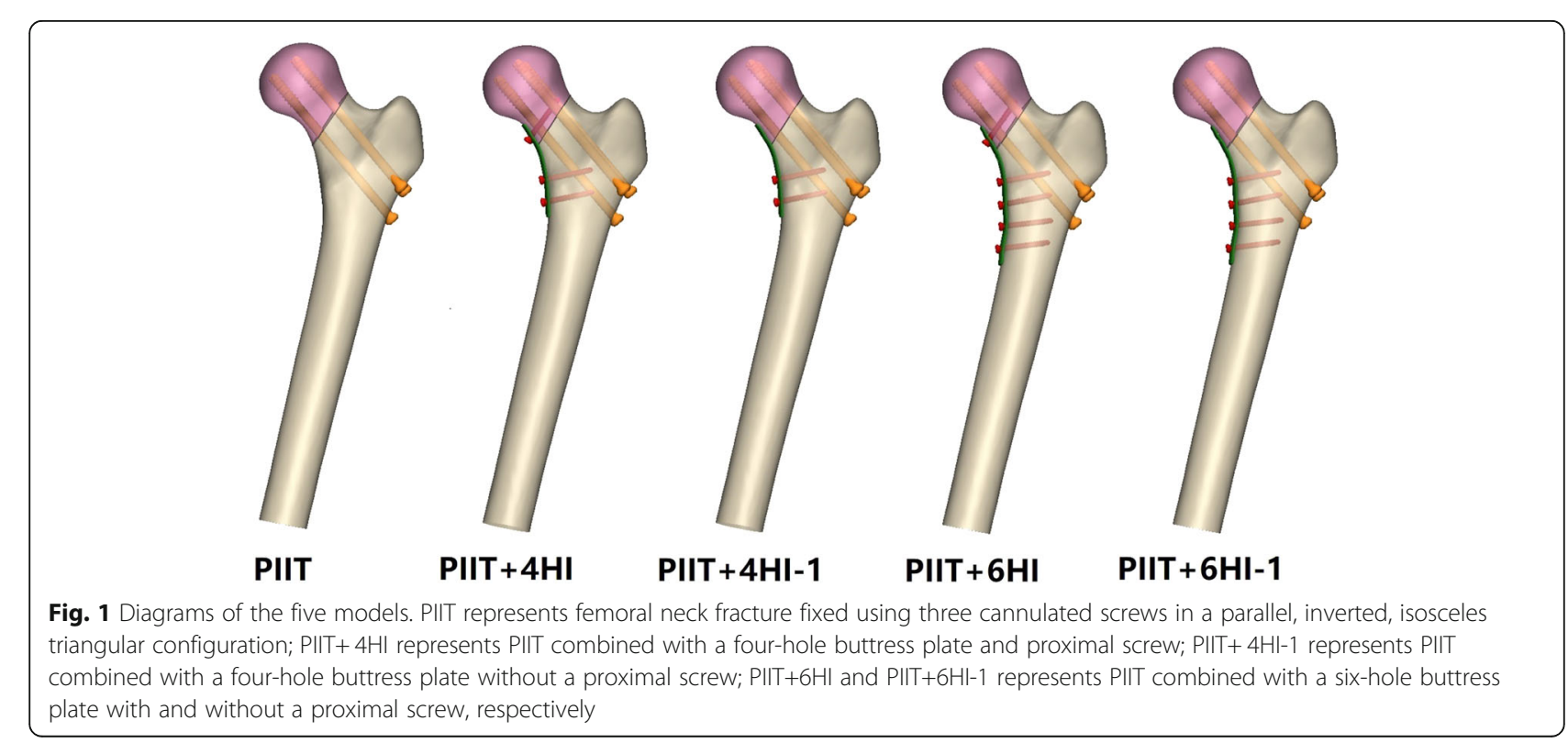


Table 1 The counts of element and node of five models

\begin{tabular}{llllll}
\hline Model & PIIT & PIIT+4HI & PIIT +4HI-1 & PIIT +6HI & PIIT +6HI-1 \\
\hline Element & 601,304 & 646,021 & 637,648 & 672,502 & 664,117 \\
Node & 135,967 & 148,678 & 146,294 & 156,165 & 153,778 \\
\hline
\end{tabular}

Abbreviations: PIIT Parallel, inverted, isosceles triangular plate configuration; PIIT+4HI Parallel, inverted, isosceles triangular plate configuration combined with a four-hole buttress plate and proximal screw; PIIT+4HI-1 Parallel, inverted, isosceles triangular plate configuration combined with a four-hole buttress plate without a proximal screw; PIIT+6HI and PIIT+6HI-1 Parallel, inverted, isosceles triangular plate configuration combined with a six-hole buttress plate with and without a proximal screw

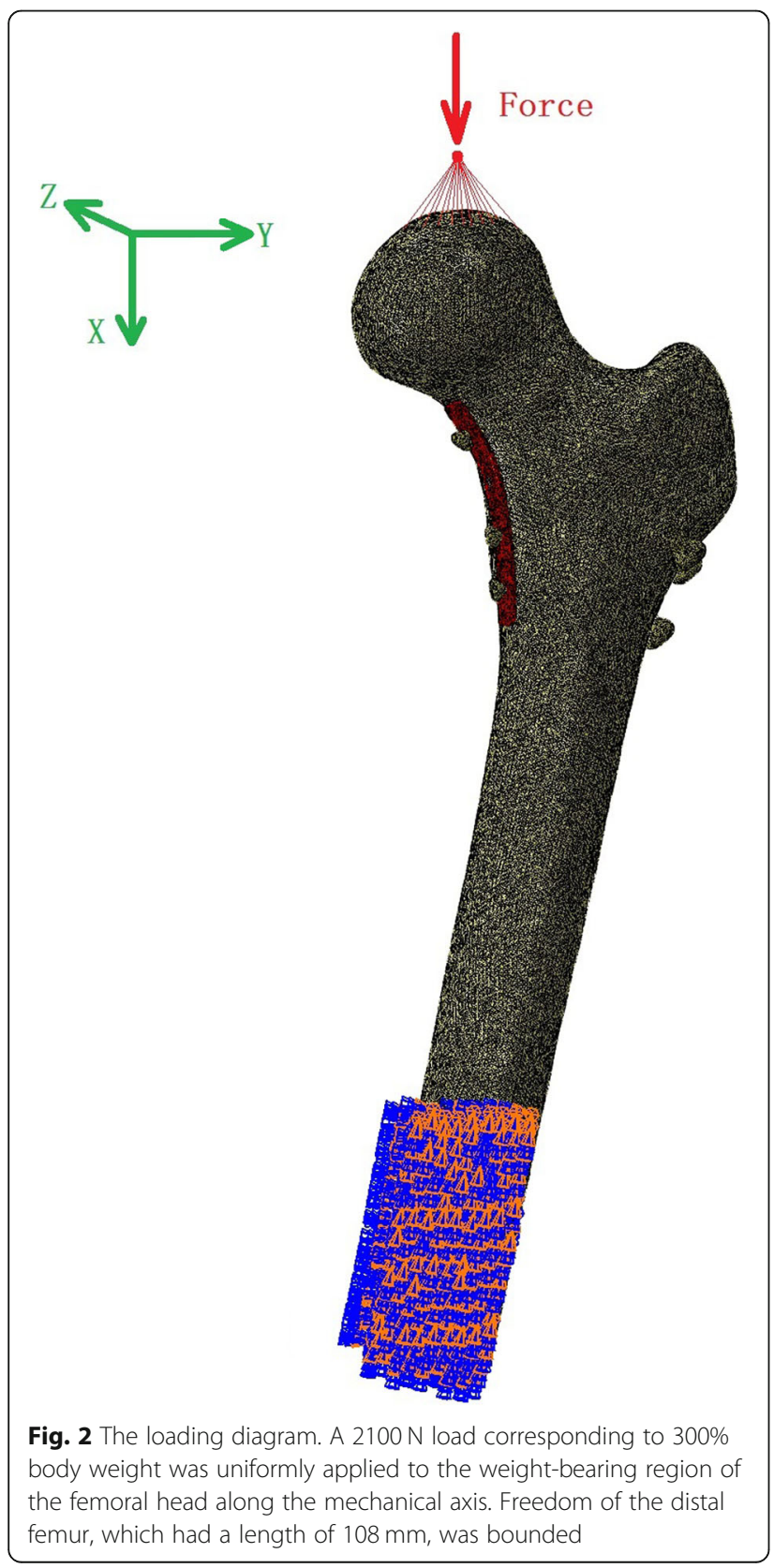

PIIT+6HI model, with a value of $1636.5 \mathrm{~N} / \mathrm{mm}$ and a variation rate of $+8.31 \%$. In contrast, $\mathrm{PIT}+4 \mathrm{HI}-1$ exhibited the poorest stiffness, with a value of $1525.8 \mathrm{~N} / \mathrm{mm}$ and a variation rate of $+0.98 \%$.

\section{Maximal stress}

The maximal stress of the plate system (MPS) in the models with a proximal screw in the buttress group was larger than that in the models without a proximal screw in the same group (795.6 \& 947.2 vs $294.9 \& 556.2$ ). The maximal stress of cannulated screws (MCS) and the maximal stress of bone (MBS) in the CS group were found to be 336.3 and $138.8 \mathrm{MPa}$. The maximal and minimal MPS values were 947.2 and 294.9 MPa in PIIT+ $6 \mathrm{HI}$ and PIIT+4HI-1, respectively. Maximal MCS and MBS values occurred in PIIT+4HI-1, with values of $335.9 \mathrm{MPa}$ (variation rate $=-0.12 \%$ ) and $138.7 \mathrm{MPa}$ (variation rate $=-0.07 \%$ ), respectively, while minimal MCS and MBS values were observed in PIIT+6HI, with values of $304.3 \mathrm{MPa}$ (variation rate $=-9.52 \%$ ) and 117.5 MPa (variation rate $=-15.35 \%$ ). The locations of maximal stress are illustrated in Fig. 3. The MCS and MBS values of the models in the buttress group were all reduced compared to those in the CS group, with variation rates of $-0.07 \%$ to $-15.35 \%$ (Table 2 ).

\section{Maximal displacement}

The maximal displacement of the internal fixation (MIFD) and the maximal displacement of bone (MBD) in the models with a proximal screw in the buttress group were smaller than those in the models without a screw in the same group (Fig. 4 \& Table 2). The variation rates of MIFD in the models with a proximal screw (PIIT+4HI \& PIIT+6HI) were $-3.41 \%$ and $-7.37 \%$, while those in the models without a proximal screw (PIIT+4HI-1 \& PIIT+6HI-1) were $-0.87 \%$ and $-4.2 \%$. The compared results of MBD regarding the variation rates between models with and without a proximal screw were similar to those of MIFD, with compared values of $-3.58 \%$ \& $-7.6 \%$ and $-0.97 \%$ \& $-4.32 \%$. The MID values of the buttress group were $6.742 \mathrm{E}-2 \mathrm{~mm}, \quad 6.626 \mathrm{E}-2 \mathrm{~mm}, \quad 7.777 \mathrm{E}-2 \mathrm{~mm}$, and $7.742 \mathrm{E}-2 \mathrm{~mm}$ for $\mathrm{PIIT}+4 \mathrm{HI}$, PIIT $+6 \mathrm{HI}$, PIIT $+4 \mathrm{HI}-1$, and PIIT+6HI-1, respectively. The MID in the CS group was $7.784 \mathrm{E}-2 \mathrm{~mm}$. All MID values in the buttress group were lower than those in the CS group, with variation rates ranging from $-0.09 \%$ (PIT $+4 \mathrm{HI}-$ $1)$ to $-14.88 \%(\mathrm{PIIT}+6 \mathrm{HI})$. The models with a proximal screw (PIIT+4HI \& PIIT+6HI) showed smaller MID values than those without (PIIT+4HI-1 \& PIIT+ $6 \mathrm{HI}-1)$, of which the variation rates ranged from $13.39 \%$ \& $-14.88 \%$ to $-0.09 \%$ \& $-0.54 \%$, respectively. 
Table 2 Categorizing of five models and their simulated results of seven parameters

\begin{tabular}{|c|c|c|c|c|c|}
\hline \multirow[b]{2}{*}{ Parameters } & \multirow{2}{*}{$\begin{array}{l}\text { CS } \\
\text { PIIT }\end{array}$} & \multicolumn{4}{|l|}{ Buttress } \\
\hline & & $\mathrm{PIIT+4HI}$ & $\mathrm{PIIT}+4 \mathrm{HI}-1$ & $\mathrm{PIIT+6HI}$ & $\mathrm{PIIT}+6 \mathrm{HI}-1$ \\
\hline Stiffness (N/mm) & 1511.0 & $1567.6(+3.75 \%)$ & $1525.8(+0.98 \%)$ & $1636.5(+8.31 \%)$ & $1580.1(+4.57 \%)$ \\
\hline MPS (MPa) & / & 795.6 & 294.9 & 947.2 & 556.2 \\
\hline MCS (MPa) & 336.3 & $313.2(-6.87 \%)$ & $335.9(-0.12 \%)$ & $304.3(-9.52 \%)$ & $335.1(-0.36 \%)$ \\
\hline MBS (MPa) & 138.8 & $118.4(-14.70 \%)$ & $138.7(-0.07 \%)$ & $117.5(-15.35 \%)$ & $138.4(-0.29 \%)$ \\
\hline MIFD (mm) & 1.262 & $1.219(-3.41 \%)$ & $1.251(-0.87 \%)$ & $1.169(-7.37 \%)$ & $1.209(-4.2 \%)$ \\
\hline $\mathrm{MBD}(\mathrm{mm})$ & 1.342 & $1.294(-3.58 \%)$ & $1.329(-0.97 \%)$ & $1.240(-7.60 \%)$ & $1.284(-4.32 \%)$ \\
\hline MID (mm) & $7.784 \mathrm{E}-2$ & $6.742 \mathrm{E}-2(-13.39 \%)$ & $7.777 E-2(-0.09 \%)$ & $6.626 \mathrm{E}-2(-14.88 \%)$ & $7.742 \mathrm{E}-2(-0.549$ \\
\hline
\end{tabular}

Abbreviations: CS Cannulated screw; MPS Maximal stress of plate and screws; MCS Maximal stress of cannulated screws; MBS Maximal stress of bone; MIFD Maximal displacement of internal fixation; MBD Maximal displacement of bone; MID Maximal relative displacement of interfragments. From the third row on, the values in brackets are the variation rates which were defined in the method

\section{Discussion}

The combination of using a buttress plate with three parallel, inverted, and isosceles triangular (PIIT) screws offers an alternative approach for stabilizing fractures with increased resistance to shear forces, with early satisfactory results $[6,7,9]$. For displaced vFNFs, especially those with comminution, this construct can prevent the inferior translation along the fracture line. Open approaches also provide the best opportunity for achieving anatomical reduction, and reduction of the apical fracture spike may dramatically increase the stability [3]. Moreover, capsulotomy allows decompression of the intra-capsular hematoma [6]. As Fig. 3 \& Fig. 4 show, in comparison with fixation using three parallel cannulated screws, the buttress plate augmented the stiffness of the structure and reduced the maximal displacement of the

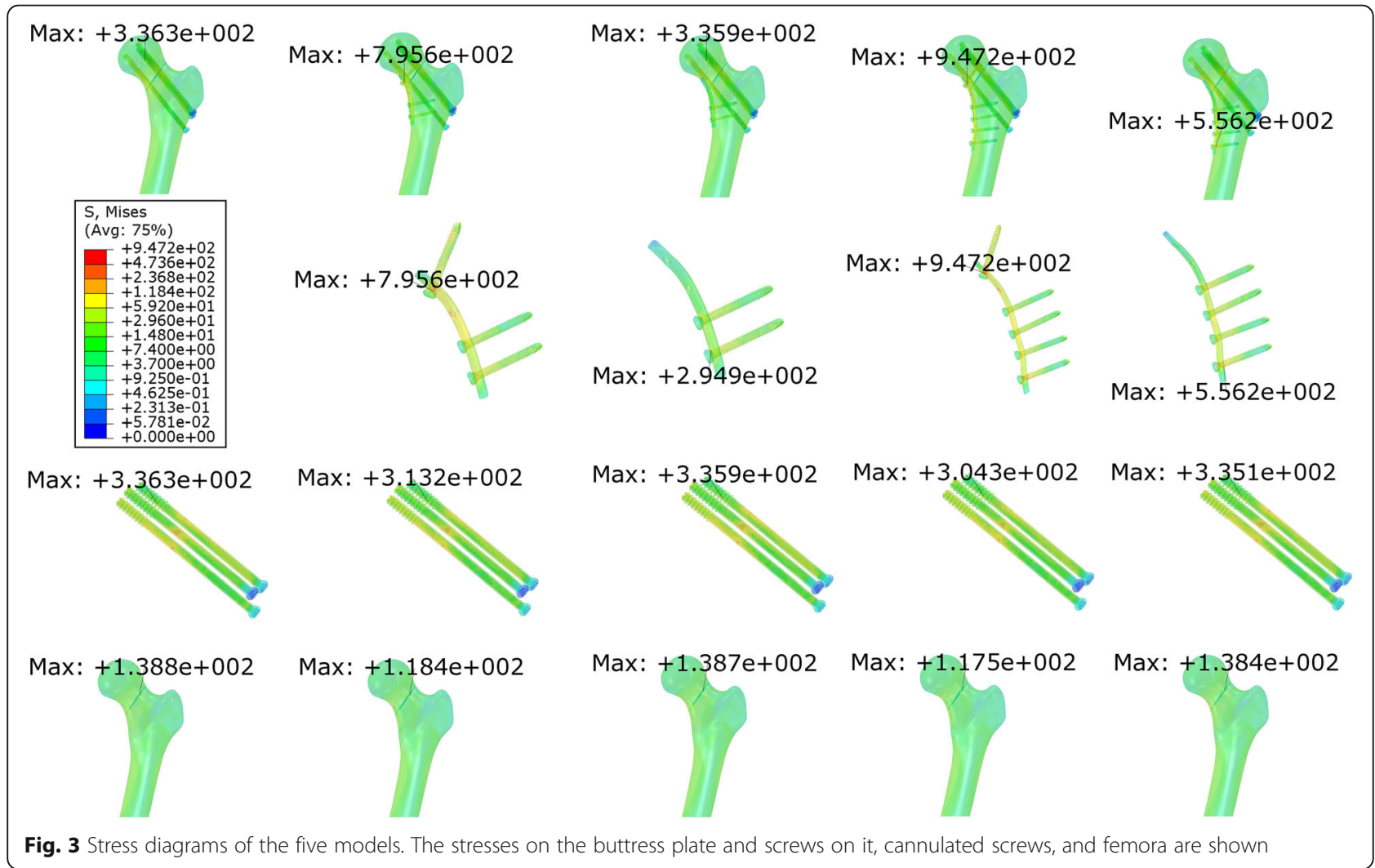




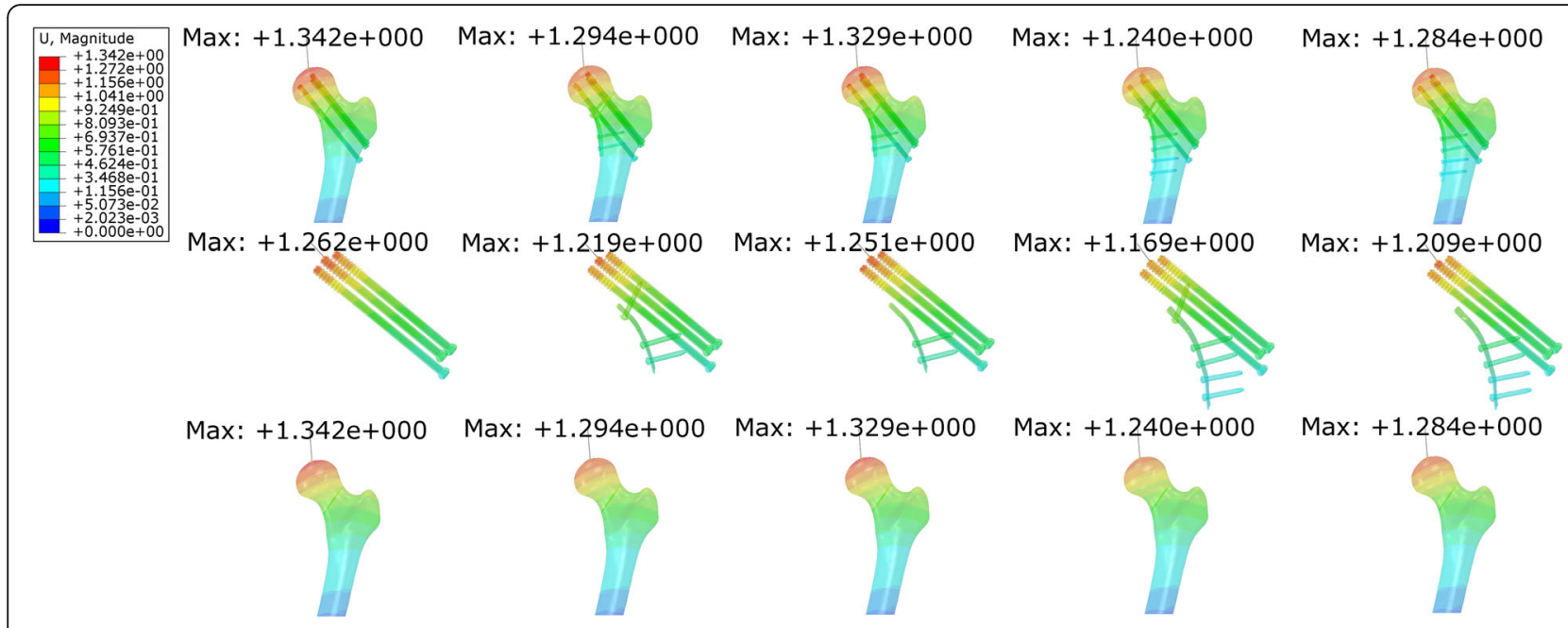

Fig. 4 Displacement diagrams of the five models. The displacements on the internal fixations (plate system and cannulated screws) and femora are shown

internal fixation and the femur, the maximal relative displacement of the fracture fragments (MIFD, MBD, MID) and the shear stress on cannulated screws (MCS) and surrounding bone (MBS). Consequently, the buttress plate improves construct mechanics, helps to resist shear force and prevents varus collapse.

However, historical failure rates still exist [9]. We found that the detailed surgical technique of the buttress plate is obscured without biomechanical evidence, for instance, whether the proximal screw is used $[6,7,9]$ and whether the proximal screw is unlocked [9] or locked [7]. In the present study, we aimed to address this uncertainty by comparing four fixed vFNF models that used two types of buttress plates over the apex of the fractures with or without proximal screws on the plates. Our pilot study found that a proximal screw locked to the buttress plate was a key technical feature contributing to transmitting force from the head to the shaft of femur and could reduce stress and displacements on the cannulated screws and bone, as well as reduce the relative displacement of fracture fragments. However, more complicated questions in terms of the "unlocked and locked" problem were associated with static and dynamic fixation concepts and could hardly be answered biomechanically, which only reflects initial stability rather than the healing process. Therefore, this problem should be left out of further studies, and "whether the proximal screw is used" should be the focus, following the fixation model of Kunapuli SC's study [7].

The stiffness of PIIT $(1511.0 \mathrm{~N} / \mathrm{mm})$ was found to be similar to that reported in previous biomechanical tests $(1418 \pm 88 \mathrm{~N} / \mathrm{mm}$ [20] and $1469.0 \pm 113.5 \mathrm{~N} / \mathrm{mm}$ [21]), indicating that our modelling method is appropriate for the evaluation of vFNFs stability. In terms of the construction choice of CSs, we used PIIT rather than a specific construction in Giordano et al.'s study [11], as PIIT is considered to provide good biomechanical stability and is more commonly used in clinical practice [9, 15]. As our aim was to investigate the biomechanics of the proximal screw, all the buttress plates in our models were placed in a standard medial position $[7,9,10]$ different from the previous study [11].

Since the buttress plate only resists vertical shear stress and protects the cannulated screw structure from failure before fracture union, Mir and Collinge did not provide any hypotheses regarding the usage of the proximal screws [6] and proximal screws are sometimes omitted in clinical cases to reduce the dynamic compression of the cannulated screws (Fig. 5). However, other studies $[7,9]$ used proximal screws to improve the reduction of shear stress. Our results are in line with the latter, showing that proximal screws are important for the augmentation of vertical shear stress in vFNFs. We observed that a greater maximal stress on buttress fixation was associated with a smaller maximal stress on the cannulated screws and bone (Table 2). The maximal stress of the models that involved a proximal screw $(\mathrm{PIIT}+4 \mathrm{HI}, \mathrm{PIIT}+6 \mathrm{HI})$ was concentrated on the junction of the plate and the proximal screw, while the maximal stress of the models without a proximal screw was concentrated on the junction of the plate and distal screw (Fig. 3). This indicates that proximal screws can help to transmit force from the head to the shaft of the femur, release stress on the cannulated screws and bone, and resist shearing.

Ye et al. reported one case of implant breakage at the screw-plate junction, representing one of three cases of implant failure [9]. Our results can explain this 


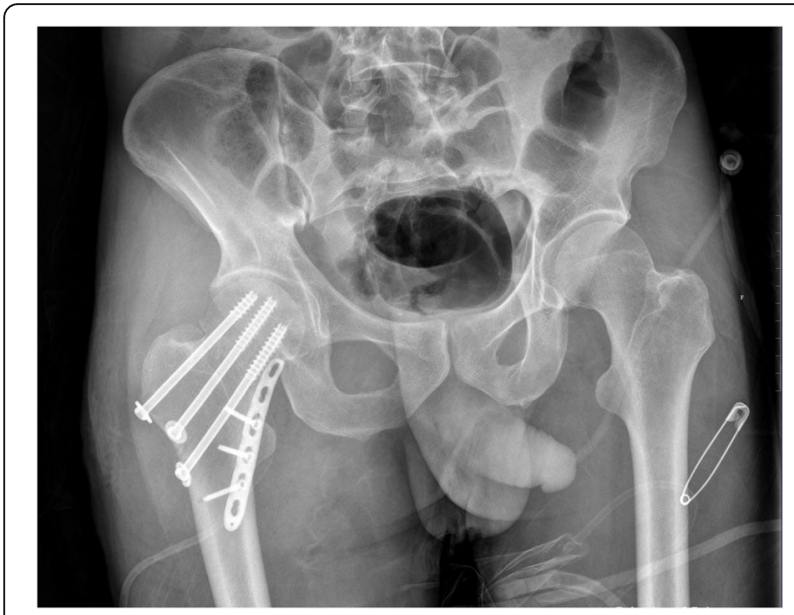

Fig. 5 Representative X-ray image of one clinical case who was treated for vertical femoral neck fracture using three cannulated screws and a buttress plate without a proximal screw

phenomenon. There was an obvious stress concentration at the screw-plate junction in all models (Fig. 3). The MPS of the models with a proximal screw at the proximal screw-plate junction (PIIT+4HI \& PIIT+6HI, 795.6 \& 947.2 $\mathrm{MPa}$ ) was even close to the yield strength of the plates (Ti-6Al-4 V-alloy, 889-921 MPa) [23]. When a proximal screw was not used, the MPS values of the buttress models (PIIT+4HI-1 \& PIIT+6HI-1) were reduced and the values $(294.9 \& 556.2 \mathrm{MPa})$ were inferior to the yield strength. It seems that non-use of proximal screws is beneficial to prevent implant breakage. However, considering the whole structure (proximal femur, three cannulated screws, and the buttress plate), the increased MPS at the proximal screw-plate junction in the models with a proximal screw in the buttress group resulted from improved resistance of the femoral head to shear and varus displacement. This is supported by the fact that the other biomechanical parameters of the same models, such as MBS, MCS, MIFD, MBD and MID, were all reduced compared with those in the models without a proximal screw in the buttress group (Table 2 ). Consequently, the proximal screw on the buttress plate, acting as a load-bearing implant [24], exhibited better fixational ability in terms of stress bearing and reduction of stress and displacement on bones and cannulated screws as well as reduction of relative displacement of fracture fragments. Furthermore, maximal MPS was observed in extreme conditions where the load applied on the femoral head was three times the body weight $(2100 \mathrm{~N})$. This is the peak theoretical load acting on the hip joint [25], which would not occur in daily life, especially for patients who have undergone internal fixation. Therefore, the stress at the proximal screw-plate junction should be treated carefully, but should not be a complete denying factor, and proximal screws are still a good choice for the initial stability of vFNFs [7].

The sliding mechanism allows linear intraoperative and postoperative compression in the treatment of vFNFs and may facilitate fracture healing [26]. Based on this principle, the dynamic fixation, such as paralleled cannulated screws, sliding hip screws and buttress plate fixation without proximal screws, was used. However, the dynamic treatment of vFNFs is also accompanied by femoral neck shortening. As a previous study reported [27], severe fracture shortening was the most common complication identified (61\%) in all failure patterns. This complication is caused by excessive resorption of bone around the fracture [28]. Severe neck shortening was classified as mechanical failure [29], as it could reduce the abductor moment and decrease the functional scores, and it may lead to local soft tissue irritation due to screws back-out [30,31] and may even increase the risk of femoral head collapse [32]. To prevent neck shortening, one type of fixation, with the used of fully threaded screws, has been suggested by some authors [33] as a length-stable strategy. Nevertheless, it had a high risk of cutting into the acetabulum because of the absence of a sliding mechanism [29]. Another type of fixation, the use of three cannulated screws plus a buttress plate using a proximal screw, is beneficial for preventing the femoral neck shortening without the risk of cutting. Most importantly, the dominant effect of the buttress plate with a proximal screw is to resist shear force across the fracture site, which is the main biomechanical problem of vertical femoral neck fractures and may also be a key factor in femoral neck shortening. Consequently, proximal screws are a reasonable consideration for preventing femoral neck shortening in vFNFs.

When buttress plates are used in vFNFs, some drawbacks should be highlighted. First, buttress plates placed on the medial side result in a possibility of hip impingement and cases have been described in previous studies $[9,34]$. Careful attention to intra-operative plate placement and avoiding the placement of buttress plates too superiorly or too anteriorly onto the femoral neck can avoid this iatrogenic impingement. However, buttress plate application should be avoided in subcapital femoral neck fractures; otherwise, the position of the plate should be as distal as possible. Transcervical and basicervical fracture patterns are more amenable patterns to be considered for the application of buttress plates, as they offer a larger footprint for hardware placement farther from the hip joint [34]. Second, for placement of the plate, an additional incision is needed, which may lead to a destruction of the blood supply. Although proper placement does not endanger blood supply to the femoral head [8], the location of the buttress plates still 
results in potential damage to inferior retinacular artery. Finally, the stress concentration at the screw-plate junction leads to a risk of fixation breakage [9], but if the implant is strong enough, it should not be problematic. There is no need for plate removal unless infection or nonunion necessitates total hip arthroplasty [7].

In conclusion, buttress plates improve construct mechanics, help to resist shear force and prevent varus collapse. The use of a buttress plate combined with a proximal screw shows better transmission of force and bears more stress, leading to the stress and displacement on cannulated screws and bone reduced, and finally improves overall stability of vFNFs.

There are some limitations in this study that should be acknowledged. First, the inserted parts of the screws were tied to the bone; thus, the screws could not detach from the bone under the load, which may have led to the overestimation of stiffness and the underestimation of MID. However, since all models in this study were set in the same way, between-sample comparisons would not have been affected. Second, due to the simplification of omitting the pressure capacity of the plate and the difficulty in contouring the buttress plate to the bone surface in actual practice, the fixation stability of the buttress plate was likely underestimated. The maximal improved stiffness determined in this study is smaller than that of Kunapuli SC et al. [7], in which the stiffness improved by $35 \%$ on average. However, the stiffness reported by Kunapuli SC et al. was only $959 \pm 257 \mathrm{~N} / \mathrm{mm}$, which is much smaller than our study and two others [20,21], indicating that their specific boundary condition may have overestimated the augmentation effects of the buttress plate. The purpose of our study was to analyse the function of proximal screws, therefore, these underestimations will not affect our conclusions. Third, Sawbone composite bone rather than cadaveric bone were used to represent young patients with good bone quality. Nevertheless, the stiffness of our constructs should not be considerably different than that of cadaveric bone models, as shown in the paper by Topp et al. [35]. Fourth, our models can only reflect initial stability, and the more complicated biomechanical conditions during bone healing process, such as secondary stability can hardly be addressed via current biomechanical methods. Finally, all the conclusions should be validated by further clinical studies.

\section{Conclusions}

Based on the FEA results, buttress plates can improve construct mechanics, help to resist shear force and prevent varus collapse; under the modelling conditions, the use of a proximal screw on buttress plate may be a key technical feature in improving anti-shearing ability; additionally, this screw may be essential to reduce stress and prevent redisplacement of cannulated screws and fracture fragments.

\section{Abbreviations}

vFNFs: Vertical femoral neck fractures; CS: Cannulated screw; FEA: Finite element analysis; MPS: The maximal stress of plate system; MCS: The maximal stress of cannulated screws; MBS: The maximal stress of bone; MIFD: The maximal displacement of internal fixations; MID: The maximal relative displacement of interfragments; PIIT: Inverted isosceles triangular configuration; VR: Variation rate; BV: Value for the buttress group; CV: Value for the CS group

\section{Acknowledgements}

The authors gratefully acknowledge the support of Dr. Xiaojuan Wei, the member of Orthopaedic Department of Shanghai Jiaotong University Affiliated Sixth People's Hospital.

\section{Authors' contributions}

SZ: Study design, data analysis, interpretation, finite element analysis, and manuscript preparation. D-JJ: Study design, manuscript preparation. SZ and D-JJ are co-first authors. JX, ML, KY and Y-HL: Data acquisition, format checking. W-TJ, $\mathrm{HH}$, and $\mathrm{C}-\mathrm{QZ}$ designed and approved the manuscript and should be considered as corresponding authors. The author (s) read and approved the final manuscript.

\section{Funding}

This study was sponsored by the National Key Research and Development Program of China (No. 2018YFC1 106300); National Natural Science Key Foundation of China (61731009); National Science Foundation of China (81572105, 31270996); Project Introduction Shanghai Municipal Education Commission-Gaofeng Clinical Medicine Grant Support (20172026); Funding Project for Talent Development in Shanghai (2017035); Interdisciplinary Program of Shanghai Jiao Tong University (YG2017QN14); Funding Project of Shanghai Sixth People's Hospital (ynlc201617). Funding bodies (61731009, YG2017QN14, ynlc201617) support the design and writing of this manuscript while the other funding bodies support the collection, analysis, and interpretation of data in this study.

\section{Availability of data and materials}

The datasets used and/or analysed during the current study available from the corresponding author on reasonable request.

\section{Ethics approval and consent to participate}

$X$-ray image acquisition was approved by Ethics Committee of Shanghai Sixth People's Hospital (Approval No. 132016-143) and a written consent was obtained from the participant.

\section{Consent for publication \\ Not Applicable.}

\section{Competing interests}

The authors are not compensated and there are no other institutional subsidies, corporate affiliations, or funding sources supporting this work unless clearly documented and disclosed.

\section{Author details}

'Orthopedic Biomechanical Laboratory of Department of Orthopedic Surgery, Shanghai Jiao Tong University Affiliated Sixth People's Hospital, NO. 600, Yishan Rd., Shanghai 200233, People's Republic of China. ${ }^{2}$ Department of Orthopedic, Fudan University Affiliated Huadong Hospital, Shanghai 200040, People's Republic of China. ${ }^{3}$ Radiology Department, Shanghai Jiaotong University Affiliated Sixth People's Hospital, Shanghai 200233, People's Republic of China. ${ }^{4}$ Department of Orthopedic Surgery, Shanghai Jiaotong University Affiliated Sixth People's Hospital, Shanghai 200233, People's Republic of China.

Received: 8 May 2020 Accepted: 1 December 2020

Published online: 12 December 2020

\section{References}

1. Liporace F, Gaines R, Collinge C, Haidukewych GJ. Results of internal fixation of Pauwels type-3 vertical femoral neck fractures. J Bone Joint Surg Am. 2008;90(8):1654-9.

2. Protzman RR, Burkhalter WE. Femoral-neck fractures in young adults. J Bone Joint Surg Am. 1976;58(5):689-95. 
3. Collinge $\mathrm{CA}$, Mir H, Reddix R. Fracture morphology of high shear angle "vertical" femoral neck fractures in young adult patients. J Orthop Trauma. 2014;28(5):270-5.

4. Panteli M, Rodham P, Giannoudis PV. Biomechanical rationale for implant choices in femoral neck fracture fixation in the non-elderly. Injury. 2015; 46(3):445-52.

5. Lu-Yao GL, Keller RB, Littenberg B, Wennberg JE. Outcomes after displaced fractures of the femoral neck. A meta-analysis of one hundred and six published reports. J Bone Joint Surg Am. 1994;76(1):15-25.

6. Mir H, Collinge C. Application of a medial buttress plate may prevent many treatment failures seen after fixation of vertical femoral neck fractures in young adults. Med Hypotheses. 2015;84(5):429-33.

7. Kunapuli SC, Schramski MJ, Lee AS, Popovich JM Jr, Cholewicki J, Reeves NP, Crichlow RJ. Biomechanical analysis of augmented plate fixation for the treatment of vertical shear femoral neck fractures. J Orthop Trauma. 2015; 29(3):144-50.

8. Putnam SM, Collinge CA, Gardner MJ, Ricci WM, McAndrew CM. Vascular anatomy of the medial femoral neck and implications for surface plate fixation. J Orthop Trauma. 2019;33(3):111-5.

9. Ye Y, Chen K, Tian K, Li W, Mauffrey C, Hak DJ. Medial buttress plate augmentation of cannulated screw fixation in vertically unstable femoral neck fractures: surgical technique and preliminary results. Injury. 2017;48(10): 2189-93.

10. Li J, Yin P, Zhang L, Chen H, Tang P. Medial anatomical buttress plate in treating displaced femoral neck fracture a finite element analysis. Injury. 2019;50(11):1895-900.

11. Giordano V, Alves DD, Paes RP, Amaral AB, Giordano M, Belangero W, Freitas A, Koch HA, do Amaral NP. The role of the medial plate for Pauwels type III femoral neck fracture: a comparative mechanical study using two fixations with cannulated screws. J Exp Orthop. 2019;6(1):-18.

12. Li J, Wang M, Li L, Zhang H, Hao M, Li C, Han L, Zhou J, Wang K. Finite element analysis of different configurations of fully threaded cannulated screw in the treatment of unstable femoral neck fractures. J Orthop Surg Res. 2018;13(1):272

13. Dubov A, Kim SY, Shah S, Schemitsch EH, Zdero R, Bougherara H. The biomechanics of plate repair of periprosthetic femur fractures near the tip of a total hip implant: the effect of cable-screw position. Proc Inst Mech Eng H. 2011;225(9):857-65.

14. Papini M, Zdero R, Schemitsch EH, Zalzal P. The biomechanics of human femurs in axial and torsional loading: comparison of finite element analysis, human cadaveric femurs, and synthetic femurs. J Biomech Eng. 2007;129(1): $12-9$.

15. Walker E, Mukherjee DP, Ogden AL, Sadasivan KK, Albright JA. A biomechanical study of simulated femoral neck fracture fixation by cannulated screws: effects of placement angle and number of screws. Am J Orthop (Belle Mead NJ). 2007;36(12):680-4

16. Machado MM, Fernandes PR, Zymbal V, Baptista F. Human proximal femur bone adaptation to variations in hip geometry. Bone. 2014;67:193-9.

17. McCartney W, MacDonald B, Ober CA, Lostado-Lorza R, Gómez FS. Pelvic modelling and the comparison between plate position for double pelvic osteotomy using artificial cancellous bone and finite element analysis. BMC Vet Res. 2018;14(1):100.

18. Eberle S, Gerber C, von Oldenburg G, Högel F, Augat P. A biomechanical evaluation of orthopaedic implants for hip fractures by finite element analysis and in-vitro tests. Proc Inst Mech Eng H. 2010;224(10):1141-52.

19. Zhang Y, Tian L, Yan Y, Sang H, Ma Z, Jie Q, Lei W, Wu Z. Biomechanical evaluation of the expansive cannulated screw for fixation of femoral neck fractures. Injury. 2011;42(11):1372-6.

20. Schaefer TK, Spross C, Stoffel KK, Yates PJ. Biomechanical properties of a posterior fully threaded positioning screw for cannulated screw fixation of displaced neck of femur fractures. Injury. 2015;46(11):2130-3.

21. Zdero R, Keast-Butler O, Schemitsch EH. A biomechanical comparison of two triple-screw methods for femoral neck fracture fixation in a synthetic bone model. J Trauma. 2010;69(6):1537-44.

22. Samsami S, Saberi S, Bagheri N, Rouhi G. Interfragmentary motion assessment for three different fixation techniques of femoral neck fractures in young adults. Biomed Mater Eng. 2016;27(4):389-404.

23. Yang D, Liu Z. Quantification of microstructural features and prediction of mechanical properties of a dual-Phase Ti-6Al-4V alloy. Materials (Basel). 2016; 9(8):628
24. Augat $P$, Bliven $E$, Hackl S. Biomechanics of femoral neck fractures and implications for fixation. J Orthop Trauma. 2019;33(Suppl 1):S27-s32.

25. Crowinshield RD, Brand RA, Johnston RC. The effects of walking velocity and age on hip kinematics and kinetics. Clin Orthop Relat Res. 1978;(132): $140-4$.

26. Nishiyama D, Matsumoto $T$, Hamazaki $H$. The treatment of femoral neck fractures: results using cephalocervical screws with sliding mechanism. Eur J Orthop Surg Traumatol. 2013;23(8):907-11.

27. Stockton DJ, Dua K, O'Brien PJ, Pollak AN, Hoshino CM, Slobogean GP. Failure patterns of femoral neck fracture fixation in young patients. Orthopedics. 2019;42(4):e376-80.

28. Sung YB, Jung EY, Kim Kl, Kim SY. Risk factors for neck shortening in patients with Valgus impacted femoral neck fractures treated with three parallel screws: is bone density an affecting factor? Hip Pelvis. 2017;29(4): 277-85.

29. Zhang B, Liu J, Zhu Y, Zhang W. A new configuration of cannulated screw fixation in the treatment of vertical femoral neck fractures. Int Orthop. 2018; 42(8):1949-55.

30. Stockton DJ, Lefaivre KA, Deakin DE, Osterhoff G, Yamada A, Broekhuyse HM, PJ OB, Slobogean GP. Incidence, magnitude, and predictors of shortening in young femoral neck fractures. J Orthop Trauma. 2015;29(9): e293-8.

31. Zlowodzki M, Brink O, Switzer J, Wingerter S, Woodall J Jr, Petrisor BA, Kregor PJ, Bruinsma DR, Bhandari M. The effect of shortening and varus collapse of the femoral neck on function after fixation of intracapsular fracture of the hip: a multi-Centre cohort study. J Bone Joint Surg Br. 2008; 90(11):1487-94.

32. Nanty L, Canovas F, Rodriguez T, Faure P, Dagneaux L. Femoral neck shortening after internal fixation of garden I fractures increases the risk of femoral head collapse. Orthop Traumatol Surg Res. 2019;105(5):999-1004.

33. Weil YA, Qawasmi F, Liebergall M, Mosheiff R, Khoury A. Use of fully threaded cannulated screws decreases femoral neck shortening after fixation of femoral neck fractures. Arch Orthop Trauma Surg. 2018;138(5): $661-7$.

34. Marchand LS, Karns M, Higgins TF, Aoki SK. Femoral neck fracture fixation with a medial buttress plate that led to impingement with hip flexion: a case report. JBJS Case Connect. 2019:9(1):e21.

35. Topp T, Müller T, Huss S, Kann PH, Weihe E, Ruchholtz S, Zettl RP. Embalmed and fresh frozen human bones in orthopedic cadaveric studies: which bone is authentic and feasible? Acta Orthop. 2012;83(5):543-7.

\section{Publisher's Note}

Springer Nature remains neutral with regard to jurisdictional claims in published maps and institutional affiliations.

Ready to submit your research? Choose BMC and benefit from:

- fast, convenient online submission

- thorough peer review by experienced researchers in your field

- rapid publication on acceptance

- support for research data, including large and complex data types

- gold Open Access which fosters wider collaboration and increased citations

- maximum visibility for your research: over $100 \mathrm{M}$ website views per year

At $\mathrm{BMC}$, research is always in progress.

Learn more biomedcentral.com/submissions 